\title{
Chemical resistance of NR/SBR rubber blends for surfaces corrosion protection of metallic tanks in petrochemical industries
}

\author{
Braihi A. J. ${ }^{1}$, Jawad A. J. ${ }^{1}$, Kadhum A. A. H., ${ }^{2,3}$, Aljibori H. S. S. ${ }^{4}$ Al-Amiery A. A. ${ }^{5}$ \\ ${ }^{1}$ Department of Polymer and Petrochemicals Industrials, College of Materials Engineering, \\ University of Babylon, Babylon, Iraq \\ ${ }^{2}$ University of Al-Ameed, Karbala, Iraq \\ ${ }^{3}$ Faculty of Engineering, Universiti Kebangsaan Malaysia, Malaysia \\ ${ }^{4}$ Faculty of Engineering, University of Warith Anbia'a, Iraq \\ ${ }^{5}$ Energy and Renewable Energies Technology Center, Baghdad University of Technology, Iraq \\ E-mail: amir1719@gmail.com
}

In this work, a series of Natural Rubber (NR)/Styrene Butadiene Rubber (SBR) blends were formulated to protect metallic petrochemical storage tanks from corrosive media. Therefore, these blends tested against a $10 \% \mathrm{HCl}$ solution for $72 \mathrm{hr}$ at room temperature. Blends series were prepared with different ratios of $N R / S B R ; 25 / 75,30 / 70,35 / 65,40 / 60,45 / 55$, $50 / 50$, and 55/45. Three types of carbon black (N-330, N-660, and $N-762)$ were added individually to the $45 / 55$ blend. Hardness, tensile strength, modulus, and elongation properties were tested before and after immersion in the $10 \% \mathrm{HCl}$ attack media. All these mechanical properties decreased after immersion action accept hardness property. Up to $45 \mathrm{phr} N R$ content, the hardness increased linearly independent on immersion action, but HCl immersion gives higher hardness values. Tensile strength increased up to $40 \mathrm{phr} N R$ content with and without immersion and the immersion action decreased tensile values. The highest elongation value obtained with 35/65 blend with and without immersion. The $45 \mathrm{phr} N \mathrm{R}$ content gives the higher modulus, while the lowest value obtained with the $30 \mathrm{phhr}$ content. For 45/55 blend, the hardness increased as the carbon black particle size decreased and immersion action gives higher hardness values. The tensile strength decreased linearly with the carbon black surface area, while with the medium surface area, the highest modulus and lowest elongation obtained.

\section{INTRODUCTION}

Metal-basic equipment is widely applied in chemical and petrochemical industries, such as valves, chemical reservoir tanks, and gas scrubbers [1]. One of the most effective methods for the protection of metals surfaces against corrosive media is coating [2], where a thin rubber film onto the surface of the metallic components can give protection from corrosion and erosion. Applications of swelling elastomer packers have an effective way of protection putting numerous wells back into the production line, through the swellable-elastomer packers' techniques [3]. The performance and compatibility of some rubber materials to mixtures of gasoline containing wide concentrations of hydrocarbons with and without $15 \%$ hydrochloric acid $(\mathrm{HCl})$ were studied [4] by exposing samples to many conditions, such as temperature, acidic strength, and brine concentrations. Two or more rubber blending types were reported to show helpful protection compared with those of individual components $[5,6]$.

Natural rubber (NR) has outstanding properties, such as good tensile, good tear strength and good abrasion resistance which are recommended to produce of O-rings, sealants, tires, conveyor belts, fluid transfer systems, body sealing systems, transmission systems, adhesives and coatings, molded parts, body parts, spare parts, automotive antivibration, etc. [7, 8]. The phenomena of strain-induced crystallization in NR improve mechanical properties. So, this behavior makes the natural rubber a candidate material in the rubber industry [9-13]. Styrene-butadiene rubber (SBR) commonly blended with NR since it has better abrasion resistance, crack initiation resistance, high filler-loading capacity, lower heat-build up behavior, and enhance it's tensile and tear ability $[7,8,14,15]$. SBR is usually used in wear related products. Thus, SBR has been used in many applications, such as sidewalls of tires, belts, hoses, footwear, foamed products, etc $[7,8]$. Mechanical properties of NR/SBR rubber blends have been studied by numerous researchers $[7,8,14,15]$. It was previously illustrated that tensile strength, modulus, elongation, hardness, and wear resistance of NR/SBR rubber blends increase with an increasing NR ratio [7, 15]. It is well-known that unreinforced rubber has a low modulus, abrasion resistance, and fatigue properties [6]. To enhance the mecha- 
nical properties of rubber materials [16], carbon black has been usually applied as a major reinforcing material of which the most interesting reinforcement, reduce the material costs, and enhancements in processing ability [17-19]. However, the main properties of carbon blacks are normally controlled by particle size, surface area, structure, and functional surface activity which in most states are related together to determine the degree of elastomer reinforcement [20]. The blend vulcanizates produced exhibit improved physical properties by judicious choice of the SBR: NR fractional ratio [21].

It is well-known that the degree of reinforcement is a combination of many factors, such as effects of physical [22-25] and chemical attachments [26, 27] between rubber chains molecules and sites of functional groups as well as sites of free radicals which found on carbon black surfaces[28]. However, some divergent views are also prevalent between the researchers in the discussion of this issue. The fact that improvement can take place, even when the matrix/fillers chemical or physical bonding is poor. It is proven by experiments using graphitized [29] and fluorinated carbon black [30]. The use of polymeric fillers interfacial interactions in the rubber mixing has shown that chemical in the form of covalent bonding is not an important condition for the development of reinforcing results. The improvement of mechanical properties due to filler rubber composites may be attributed to chemical interaction among the functional groups with carbon black [31]. The rubber performance and the mechanism of reinforcement are influenced by the basic properties of carbon blacks. The enhancement properties of rubber blends, for instance, are the tear strength, tensile strength, and abrasion resistance, apart from improving the hardness and modulus as a result of improvements by reinforcement using carbon black [32-34]. This improvement is usually accepted that, to a large extent, dependent on the physical interactions bonding between the elastomer matrix and its filler ingredients. The surface characteristics, structure, and particularly carbon particle size are the main factors evaluating the reinforcing effects of fillers in rubber blends lining of rubber for metallic surfaces consists of NR/SBR rubber blend formulations namely ebonite has covered the interest of petrochemical and chemical industries [35]. Rubber lining has interesting specifications in the aspect of chemical-mechanical properties, ease of handling, and low cost. However, rubber blends have two properties distinguishing them from most other typical materials: they can absorb large quantity of solvent molecules by occupying the pores and free volume and then the solvent molecules diffusion into the rubber matrix without getting dissolved and the solvent trapped in the pores penetrate into the network of the polymer chains and may have high deformations with little stresses [36]. Upon exposure to different chemical materials, the properties of elastomers mostly undergo property shifting. One of the most significant effects is the swelling property due to the formation of a cross-linked network structure. The swelling parameter depending on the base rubber and solution. The swelling degree has a wide range from negligible to slight to quite large degrees up to a few hundred percents. The swelling solutions may interact with chemical components in the rubber's metrics in which effect the mechanical and/or processing properties. By using swelling media such as water, oil, or acids/bases can cause simple volume increase or functional group effects [37]. When a rubber blend is immersed in a suitable solution, the fluid molecules penetrate into the rubber network structure and swell the rubber metrics and produce affection on various properties. The swelling degree depends on the solvent affinity with the material and the crosslink density [38-41]. The main goal of this research is to determine the effect of NR rubber and carbon black type on a rubber compound and to obtain the best chemical resistance of NR/SBR blend for lining applications.

Tab. 1. Rubber ingredients with different fraction ratios of NR (25-55) phr

\begin{tabular}{|l|c|c|l|}
\hline Component & phr & Chemical formula & Function \\
\hline Natural rubber (NR) & $25-55$ & $\mathrm{C}_{5} \mathrm{H}_{8}$ & Matrix component \\
\hline Styrene Butylene Rubber (SBR) & $75-45$ & $\mathrm{C}_{12} \mathrm{H}_{14}$ & Matrix component \\
\hline Zinc oxide & 8 & $\mathrm{ZnO}$ & Activator agent \\
\hline Stearic acid & 1.45 & $\mathrm{C}_{18} \mathrm{H}_{36} \mathrm{O}_{2}$ & Activator agent of an accelerator \\
\hline Paraffinic oil & 3 & $\mathrm{C}_{n} \mathrm{H}_{2 \mathrm{n}+2}$ & Extender or diluent \\
\hline Sulfur & 5.63 & $\mathrm{~S}_{8}$ & Vulcanization agent \\
\hline N-(1,3-dimethylbutyl)-N-phenyl-p-phynelenediamine & 2 & $\mathrm{C}_{18} \mathrm{H}_{24} \mathrm{~N}_{2}$ & \\
\hline Cyclohexylthiophthalimide (CTP-100) & 0.4 & $\mathrm{C}_{14} \mathrm{H}_{15} \mathrm{NO}_{2} \mathrm{~S}$ & $\begin{array}{l}\text { Pre-vulcanization inhibitor/cure retarder } \\
\text { (Anti-scorching agent) }\end{array}$ \\
\hline Carbon black & 72 & $\mathrm{C}$ & Reinforcing agent \\
\hline Phenolic resin & 0.8 & Formaldehyde - base & Adhesive agent \\
\hline
\end{tabular}




\section{EXPERIMENTAL PART}

\section{Materials}

NR and SBR materials were provided by Babel tier company, Al Hillah city-Iraq, while other ingredients were purchased from Aldrich.

\section{Sample Preparation}

Series of seven rubric masterbatches were prepared based on NR/SBR blends as follows: 25/75, 30/70, $35 / 65,40 / 60,45 / 55,50 / 50$, and 55/45 part per hundred rubber part (phr) with the addition of a constant amount of suitable ingredient as shown in Table 1. Then these blends were immersed for $72 \mathrm{hr}$ in a $10 \% \mathrm{HCl}$ aqueous solution at room temperature according to ASTM D-471. Three types of carbon black added individually to the 45/55 blend. These types are N-330, N-660, and N-762.

\section{Tests}

Mechanical properties for the prepared blends, such as modulus, tensile strength, and elongation, were measured using a Monsanto T10 tensile tester machine according to the ASTM D-412 standard testing method under the speed of a crosshead about $50 \mathrm{~mm} \mathrm{~min}^{-1}$ and a temperature around $25^{\circ} \mathrm{C}$. For the tensile test, dumbbell samples ( $2 \mathrm{~mm}$ thick) were used and the average value for three samples was recorded. Hardness test carried out by Wallace Dead Load Hardness Tester according to ASTM D-1415 using disk samples (3 mm thick and $45 \mathrm{~mm}$ diameter) and for 30 second penetration time. The average value for five readings was adopted by the International Rubber Hardness Degree (IRHD) units.

Tab. 2. Density and particle size of the used carbon black types

\begin{tabular}{|c|c|c|c|}
\hline $\begin{array}{c}\text { Carbon } \\
\text { black type }\end{array}$ & $\begin{array}{c}\text { Specific density } \\
(\mathbf{g} / \mathbf{l})\end{array}$ & $\begin{array}{c}\text { Particle size } \\
(\mathbf{n m})\end{array}$ & $\begin{array}{c}\text { Surface area } \\
\left(\mathbf{m}^{2} / \mathbf{g}\right)\end{array}$ \\
\hline N-330 & 375 & $26-30$ & $83 \pm 6$ \\
\hline N-660 & 425 & $49-60$ & $36 \pm 5$ \\
\hline N-762 & 505 & $61-100$ & $25-33$ \\
\hline
\end{tabular}

\section{RESULTS AND DISCUSSIONS}

\section{Hardness}

Figure 1 shows the hardness of the prepared blends before and after immersing in a $10 \% \mathrm{HCl}$ solution for 72 hours at room temperature. Before immersing the hardness increases with increasing the NR content up to $45 / 55$ (NR/SBR) ratios. This may attribute to the increment in the crystalline portion in the blend, which is the NR component. By increasing this portion, the indenter penetration ability decreased due to the high alignment of chains within the blend structure. Beyond the $45 / 55$ ratio, the hardness decreased slightly. This can be referred to the phase separation between the blend components. This separation increases the free volume slightly within the blend network and facilities the penetration action.

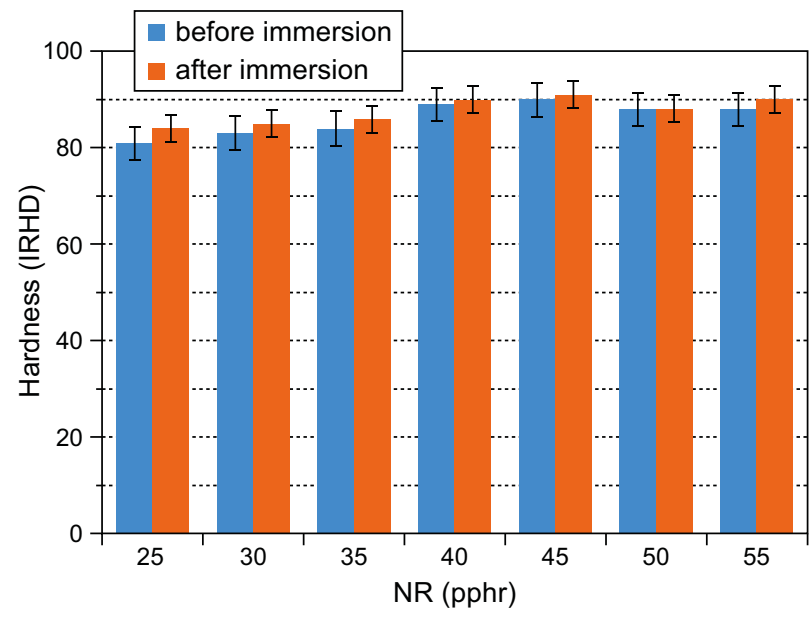

Fig. 1. Hardness of NR/SBR blends before and after immersion in a $10 \% \mathrm{HCl}$ solution

After immersion in a $10 \% \mathrm{HCl}$, the elastomeric blends have the same behaviors, but with higher hardness values. This means that $\mathrm{HCl}$ molecules diffuse through the structure of the blend and make cross-linking to some extent due to the ability of ions $\mathrm{H}^{+}$and $\mathrm{Cl}^{-}$ in the $\mathrm{HCl}$ solution. This cross-linking raises the hardness slightly because it occurs by secondary forces (hydrogen bonding), not by primary bonds. In other words, these increments in hardness proved that these elastomeric blends resist the acidic action in the lining applications.

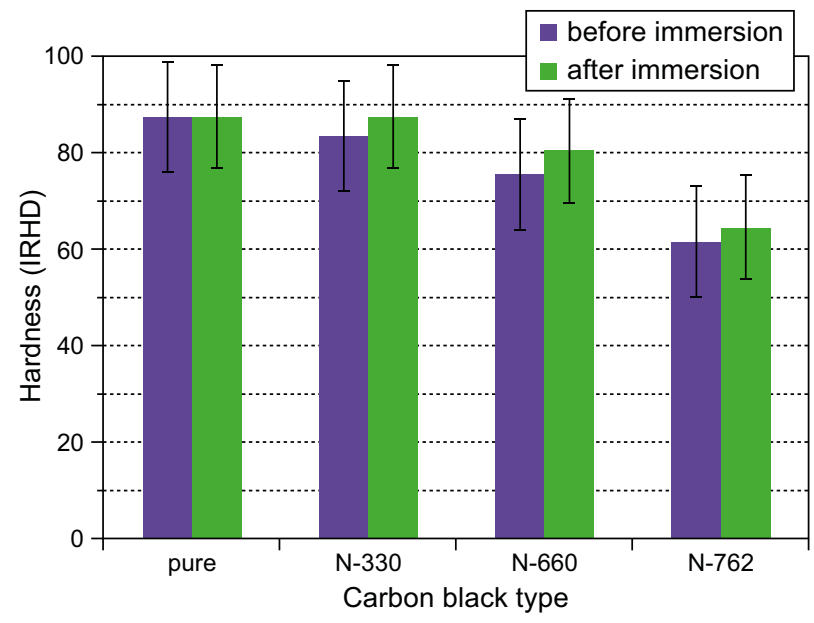

Fig. 2. Hardness of NR/SBR blends with different types of carbon black before and after immersion in a $10 \% \mathrm{HCl}$ solution 
The effect of the particle size of the reinforcing agent (carbon black) as shown in Figure 2. This figure represents the hardness values for 45/55 blend using three types of carbon black which differ in their particle sizes as given in Table 2. The hardness increased as the particle size decreased. This is can be attributed to the surface area $(P)[40]$ of carbon black increased as its diameter $(d)$ decreased according to Equation 1. Therefore, the reinforcing factor $\left(R_{f}\right)$ increased, since this factor is the result of the surface area $(P)$ times the surface activity $\left(S_{\text {act. }}\right)$, as shown in equation 2 .

$$
\begin{aligned}
P & =\pi \cdot d^{2} \\
R_{f} & =P \cdot S_{\text {act }}
\end{aligned}
$$

The carbon black surfaces possess many active functional groups, such as $\mathrm{OH}^{-}, \mathrm{COOH}^{-}, \mathrm{C}=\mathrm{O}$, etc., which enable it to create many interactions with the elastomeric matrix. These new forces enhance penetration resistance (hardness). This figure shows, also the effect of acidic immersion. The same behavior repeated there; the hardness increased after immersion. This is another evidence of the cross-linking findings.

\section{Tensile strength}

Figure 3 represents the tensile strength of prepared blends (before and after immersion in a $10 \% \mathrm{HCl}$ solution), while Figure 4 monitors the effect particle size of carbon black. First, by increasing the NR content in the blend, tensile strength values exhibited a fluctuating manner. But generally, there is an increment that appeared in the $40 / 60$ (NR/SBR) blend. However, this instability reflexes the uneven distribution of the reinforcing agent (carbon black) within the blend structure with maintaining its reinforcing ability. This is an expected tendency due to the high viscosity of the elastomeric matrix. This difficulty can be overcome by ionization

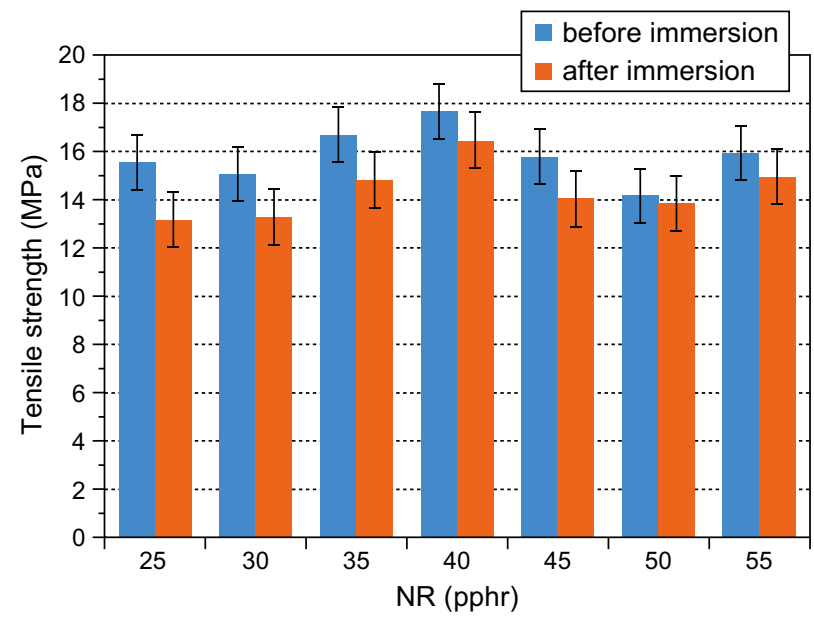

Fig. 3. Tensile strength of NR/SBR blends before and after immersion in a $10 \% \mathrm{HCl}$ solution mixing. In all blends, the tensile strength decreased after immersion. This may be due to the solvent molecules penetrate the structure, extended the distance between elastomeric chains, and destroyed some of the secondary forces among chains. The tensile strength increased as the particle size of carbon black increased (Fig. 4). This means that the contribution of carbon black particles in bearing the applied load (tensile mode) as greater than reinforcing agents. In another meaning, as the particle size can be greater, the bearing ability can be higher.

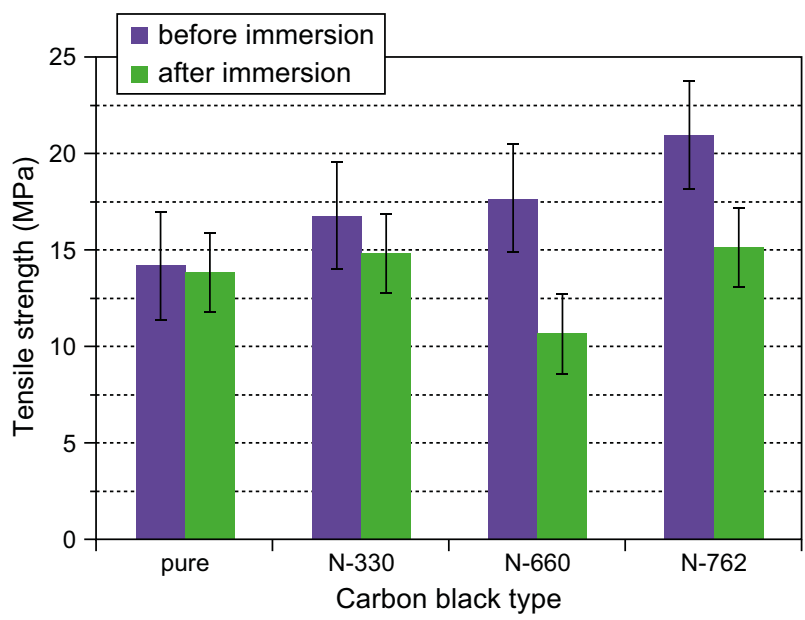

Fig. 4. Tensile strength of NR/SBR blends with a different type of carbon black before and after immersion in a $10 \% \mathrm{HCl}$ solution (pure sample was carbon black free)

\section{Elongation}

The elongation results of the prepared blends (before and after immersion), as well as the influencing of the particle size on this property, have been plotted in Figures 5 and 6, respectively. The 35/65 (NR/SBR) blend seems to be with the highest elongation value.

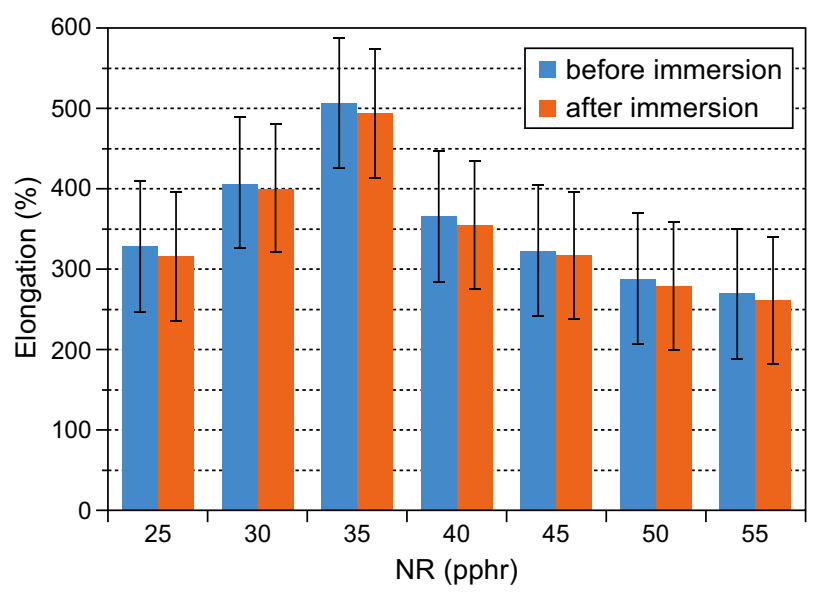

Fig. 5. Elongation values of NR/SBR blend before and after immersion in a $10 \% \mathrm{HCl}$ solution 
Moreover, the penetration activity has the highest value due to the amorphous tendency (nature) of this blend. The effect of carbon black type upon the elongation was shown interesting values as in Figure 6. By using three types of carbon black with different particles size. the $\mathrm{N}-330$ type gives the highest elongation, while the type $\mathrm{N}-660$ gives the lowest values.

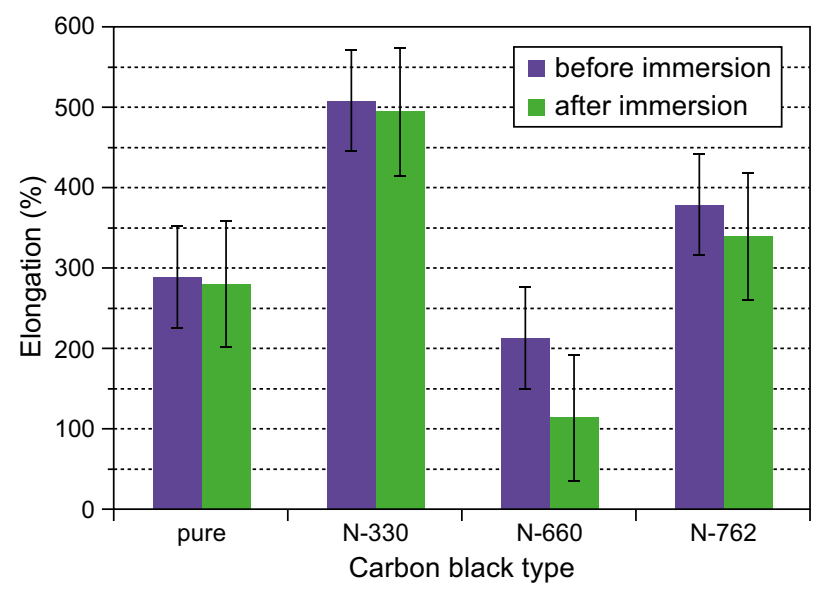

Fig. 6. Elongation values of NR/SBR blend with different types of carbon black before and after immersion in a $10 \%$ $\mathrm{HCl}$ solution

\section{Modulus}

Modulus values of rubber blend before and after immersion in a $10 \% \mathrm{HCl}$ solution was shown in Figure 7, while the affection of carbon black was represented in Figure 8. In general, the adding of NR content change the modulus in random way, as a result of high number of factors which effect of behavior values of rubber blends. However, the higher value of modulus obtained with 45 phr NR content, while the lowest value with the $30 \mathrm{phr}$ content. On the other hand, the immersion

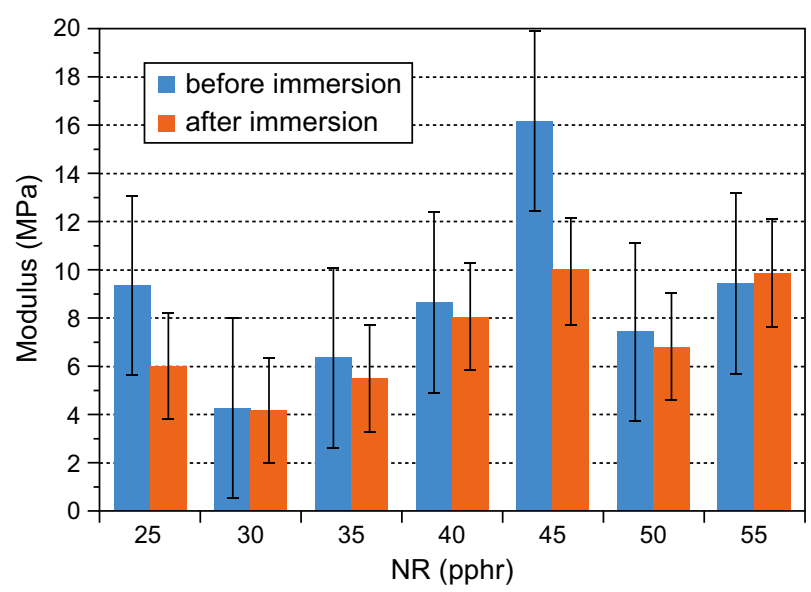

Fig. 7. Modulus of NR/SBR blends before and after immersion in a $10 \% \mathrm{HCl}$ solution of blends in $\mathrm{HCl}$ solution has reducer effect on modulus results for all samples, as well as the $45 / 55$ blend has the highest values was before and after immersion. The behavior may be explained due to the high ability of $\mathrm{HCl}$ solution ions to inter and penetrate between chains of rubber blends to increase the elongation and flexibility. Also, using different particles size of carbon black have a dramatic effect on modulus values. One of the most important results that, moderate particle size $(\mathrm{N}-660)$ has the best effect on modulus due to the sufficient size to occupy the spaces and affinity between chains to make attraction forces in rubber blends.

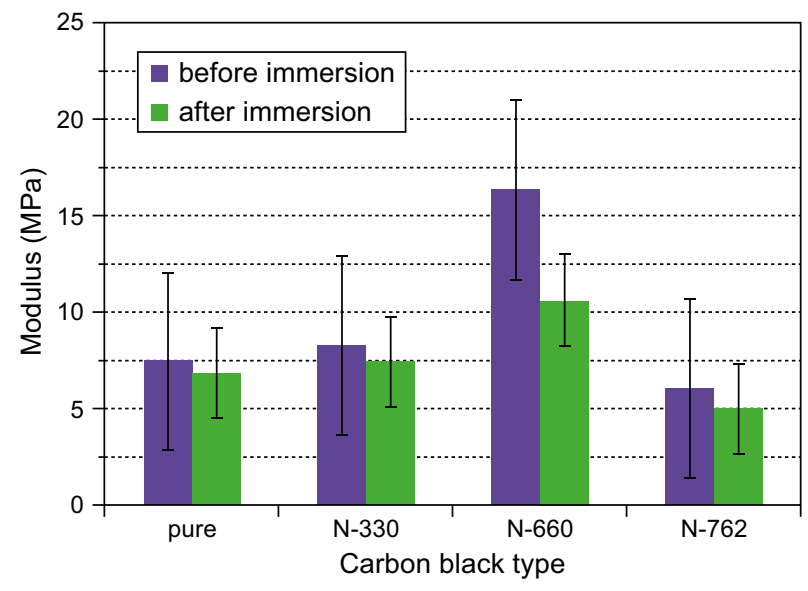

Fig. 8. Modulus values of NR/SBR blend with different types of carbon black before and after immersion in a $10 \%$ $\mathrm{HCl}$ solution

\section{CONCLUSIONS}

In general, all the mechanical properties decreased after immersion in $10 \%$ of $\mathrm{HCl}$ solution action accept hardness property in which increased with increasing the NR content up to $45 \mathrm{phr}$ before and after immersing, but $\mathrm{HCl}$ immersion gives higher hardness values due to chemical reactivity and selectivity of, electro-negativity, hardness and softness as has been reported Elsewhere [42]. The tensile strength increased up to $40 \mathrm{phr}$ NR content with and without immersion and the immersion action decreased tensile values. The general trend shows a variation within $\pm 1.6 \mathrm{Mpa}$, and also increases linearly with the carbon black particle size. The highest elongation was recorded for the sample with blend of 35/65 NR/SBR and N330 carbon black. The higher modulus obtained with $45 \mathrm{phr}$ NR content, while the lowest value with the $30 \mathrm{phr}$ content. The maximum value for the hardness was observed in sample with blend 45/55 and N330 carbon black. The sample with $45 / 55$ give a heist module also in both before and after immersion and give high reading when N660 was used. 


\section{REFERENCES}

1. Groysman A.: Corrosion problems and solutions in oil, gas, refining, and petrochemical industry. Koroze an ochrana materiálu 2017, 61 (3), 100-117.

2. Behzad Fotovvati; Navid Namdari; Amir Dehghanghadikolaei: On Coating Techniques for Surface Protection A Review. Journal of Manufacturing and Materials Processing 2019, 3 (1), 28.

3. Al-Douseri K.M.M.; Barnes C.; Young D.; Smith P.E.: Swellable packers provide a brownfield water management solution in open and cased hole, SPE Oil and Gas India Conference and Exhibition 2010, 1-8.

4. Ertekin A.; Sridhar N. Performance of Elastomeric Materials in Gasoline-Ethanol Blends - A Review. Corrosion 2009, NACE \# 09533.

5. Tuo Lei; Yong-Wang Zhang; Dong-Liang Kuang; Yong-Rui Yang: Preparation and Properties of Rubber Blends for High-Damping-Isolation Bearings. Polymers 2019, 11 (8), 1-18.

6. Kaushik Pal; Samir K. Pal; Chapal K.Das; Jin Kuk Kim: Influence of fillers on NR/SBR/XNBR blends Morphology and Wear. Tribology International 2009, 43 (8), 81542-1550.

7. Auda J. Braihi, Jaleel K. Ahmed, Ban J. Khadim and Nabil H. Hameed: Effect of Graphite on the Properties of Natural Rubber. Journal of Babylon University/Engineering Sciences 2016, 24 (3), 617-624.

8. Tangudom P.; Thongsang S.; Sombatsompop N.: Cure and mechanical properties and abrasive wear behavior of natural rubber, styrene-butadiene rubber and their blends reinforced with silica hybrid fillers. Mater Design 2014, 53, 856-864.

9. Poompradub S.; Tosaka M.; Kohjiya S.; Ikeda Y.; Toki S.; Sics I.; Benjamin S. Hsiao: Mechanism of strain-induced crystallization in filled and unfilled natural rubber vulcanizates. J Appl Phys 2005, 97, 103529.

10. Huneau B.: Strain-Induced Crystallization of Natural Rubber - A Review of X-Ray Diffraction Investigations. Rubber Chem Technol 2011, 84, 425-452.

11. Mohammed H. Al-Mammory, Najim A. Saad and Auda j. Braihi: Design and Prepared of a New Rubber Composite for Absorption of Vibration in Electrical Generator, The Iraqi Journal of Mechanical and Material Engineering 2009, 9 (3), 383-393.

12. Le Cam J.B.; Toussaint E.: The Mechanism of Fatigue Crack Growth in Rubbers under Severe Loading: The Effect of Stress-Induced Crystallization. Macromolecules 2010, 43, 4708-4714.

13. Mars W.V.; Fatemi A.: Multiaxial stress effects on fatigue behavior of filled natural rubber. Int J Fatigue 2006, 28 , 521-529.

14. George S.C.; Ninan K.N.; Groeninickx G.; Thomas S.: Styrene-butadiene rubber/natural rubber blends: Morphology, transport behavior, and dynamic mechanical and mechanical properties. J Appl Polym Sci 2000, 78, 1280-1303.

15. Varkey J.T.; Augustine S.; Groeninckx G.; Bhagawan S.S.; Rao S.S.; Thomas S.: Morphology and mechanical and viscoelastic properties of natural rubber and styrene butadiene rubber latex blends. J Polym Sci Pol Phys 2000, 38 , 2189-2211.
16. Sivaselvi K., Kandasamy Gopal: Study to enhance the mechanical properties of natural rubber by using the carbon black (N550). Materials Today 2020, 26, 378-381.

17. Kaushik pal R. Rajasekar; Dong Jin Kang; Zhenxiu Zhang; Samir Kumar Pal; Chapal K. Das; Jin Kuk Kim: Effect of Filler and Urethane Rubber on NR/BR with Nanosilica: Morphology and Wear. Journal of Thermoplastic Composite Materials 2010, 11, 717-739.

18. Heinrich G.; Klüppel M.; Vilgis T.A.: Reinforcement of Elastomers. Current Opinion in Solid State \& Materials Science 2002, 6 (3), 195-203.

19. Chung Ho Shin; Dae Su Kim: Effects of rubber type on the curing and physical properties of silica filled rubber compounds. Polymer. Adv. Technol 2008, 19, 1062-1068.

20. Michael E. Spahr; Roger Rothon: Carbon Black as a Polymer Filler. Polymers and Polymeric Composites: A 2016, 1-31.

21. Naskar N.; Debnath SC and Basu D.K.: Novel method for preparation of carboxylated nitrile rubber-natural rubber blends using bis(diisopropyl) thiophosphoryl polysulfides. J Appl Polym Sci 2001, 80 (10), 367.

22. Wen Fu; Li Wang; Jianning Huang; Cuiwen Liu; Wenlong Peng; Haotuo Xiao; Shenglin Li: Mechanical Properties and Mullins Effect in Natural Rubber Reinforced by Grafted Carbon Black Advances in Polymer Technology 2019, ArticleID 4523696.

23. Puchong Thaptong; Chakrit Sirisinha; Uthai Thepsuwan; Pongdhorn Sae-Oui: Properties of Natural Rubber Reinforced by Carbon Black-based Hybrid Fillers. PolymerPlastics Technology and Engineering 2014, 53 (8), 818823.

24. Ismail H.; Nordin R.; Noor A. M.: The Effect of Filler Loading on Curing and Mechanical Properties of Natural Rubber/recycled Rubber Powder Blends International Journal of Polymeric Materials and Polymeric Biomaterials 2006, 54 (1), 9-20.

25. Fei Zhao; Weina Bi; Shugao Zhao: Influence of Crosslink Density on Mechanical Properties of Natural Rubber Vulcanizates. Journal of Macromolecular Science, Part B Physics 2011, 1460-1469.

26. Zhao Fei; Chen Long; Pan Qingyan; Zhao Shugao: Influence of Carbon Black on Crosslink Density of Natural Rubber. Journal of Macromolecular Science, Part B 2012, 1208-1217.

27. Rubber Qiuying Li; Yulu Ma; Chifei Wu; Shengying Qian: Effect of Carbon Black Nature on Vulcanization and Mechanical Properties of Rubber. Journal of Macromolecular Science, Part B 2008, 837-84.

28. Nagornaya M.N.; Razdyakonova G.I.; Khodakova S.Y.: The effect of functional groups of carbon black on rubber properties. International Conference on Oil and Gas Engineering, OGE-2016 Procedia Engineering 2016, 152, 563-569.

29. Panel K. Song: Micro- and nano-fillers used in the rubber industry, Progress in Rubber Nanocomposites, Woodhead Publishing Series in Composites Science and Engineering 2017, 41-80.

30. Kyung Hoon Kim; Min-Ji Kim; Ji Wook Kim; Kyeong Min Lee; Hyeong Gi Kim; Young-Seak Lee, Enhanced creep behavior of carbon black/epoxy composites with high dispersion stability by fluorination. Carbon Letters 2019, 29, 643-648. 
31. Dipankar Mondal; Soumyajit Ghorai; Dipak Rana; Debapriya De; Dipankar Chattopadhyay: The rubber-filler interaction and reinforcement in styrene butadiene rubber/ devulcanize natural rubber composites with silica-graphene oxide. Polymer composites 2018, E1559-E1572.

32. Maochuan Gao; Feng Zheng; Jinjia Xu; Shangyong Zhang; Sanjana S. Bhosale; Junjie Gu; Ruoyu Hong: Surface modification of nano-sized carbon black for reinforcement of rubber. Nanotechnology Reviews 2019, 8 (1), 405-414.

33. Xiang-Wen Zhou ; Yue-Feng Zhu; Ji Lian, Preparation and properties of powder styrene-butadiene rubber composites filled with carbon black and carbon nanotubes. Materials Research Bulletin 2007, 42 (3), 456-464.

34. Fröhlich J.; Niedermeier W.; Luginsland H.D.: The effect of filler-filler and filler-elastomer interaction on rubber reinforcement. Composites Part A Applied Science and Manufacturing 2005, 36 (4), 449-460.

35. Iraj Rezaeian; Payam Zahedi; Motahareh Sadat Loghmani: Formulation and curing characteristics of EPDM/NR and EPDM/SBR polyblends used In metallic surfaces rubber lining. Journal of Applied Polymer Science 2009,113 (2), 849-854.

36. Monika Zielińska; Roger Seyger; Wilma K. Dierkes; Dariusz Bielinski; Jacques W.M. Noordermeer: Elastomery Swelling of EPDM rubbers for oil-well applications as influenced by medium composition and temperature Part I. Literature and theoretical background. kwiecien czerwiec, Elastomery 2016, 6-17.
37. Mohammed H. Al-Maamori; Ali I. Al-Mosawi; Shaymaa Abbas Abdulsada, Mechanical Properties of Hybrid Elastomer Blends. Journal of Thin Films, Coating Science Technology and Application 2017, 4 (1), 13.

38. Bulat A. F.; Dyrda V. I.; Lysytsya M. I.; Grebenyuk S. M.: Numerical Simulation of the Stress-Strain State of ThinLayer Rubber-Metal Vibration Absorber Elements Under Nonlinear Deformation. Strength of Materials 2018, 50 (3), 387-395.

39. Mansilla M.A.; Marzocca A.J.; Macchi C.; Somoza A.: Natural Rubber/Styrene-Butadiene Rubber blends prepared by solution mixing: Influence of vulcanization temperature using a Semi-EV sulfur curing system on the microstructural properties. Polymer Testing 2017, 63, 150-157.

40. Van Alphen, J.: "RUBBER CHEMICALS" Redial publishing company, Holland, 1973.

41. Akram J. J., Auda J. B. and Farhan, L. R.: Polymeric Additives in Crude Oil Pipelines. Lambert Academic Publishing, ISBN: 978-620-2-67878-0. 2020.

42. Abdul Hameed Alobaidy; Abdulhadi Kadhum; Shaimaa B. Al-Baghdadi; Ahmed A. Al-Amiery; Abdul Amir H. Kadhum; Emad yousif; Abu Bakar Mohamad: EcoFriendly Corrosion Inhibitor - Experimental Studies on the Corrosion Inhibition Performance of Creatinine for Mild Steel in $\mathrm{HCl}$ Complemented with Quantum Chemical Calculations. Int. J. Electrochem. Sci. 2015, 10, 3961-3972. 